\title{
Representações Sociais de Universitários com Deficiência Física sobre a
}

\author{
Sexualidade das Pessoas com Deficiência
}

\author{
Alana Nagai Lins de Carvalho* \\ Universidade Federal de Sergipe - UFS, São Cristóvão, SE, Brasil \\ ORCID: https://orcid.org/0000-0002-8676-5682 \\ Joilson Pereira da Silva** \\ Universidade Federal de Sergipe - UFS, São Cristóvão, SE, Brasil \\ ORCID: https://orcid.org/0000-0001-9149-3020
}

\begin{abstract}
RESUMO
O principal objetivo deste estudo foi identificar e analisar as representações sociais de universitários com deficiência física, sobre a sexualidade das pessoas com deficiência. Participaram voluntariamente 10 acadêmicos com deficiência física, de ambos os sexos, com idade igual ou superior a 18 anos, que foram submetidos a um roteiro de entrevista semiestruturado, associado a um questionário sociodemográfico. A análise foi desenvolvida através do software Interface de $R$ pour les Analyses Multidimensionnelles de Textes et de Questionnaire (IRAMUTEQ) por meio de uma Classificação Hierárquica Descendente (CHD) e da estatística descritiva com uso do pacote estatístico Statistical Package for the Social Sciences (SPSS). O dendrograma apresentou como resultados o conceito e a vivência da sexualidade, a participação familiar, a importância dada ao corpo, a construção da identidade como pessoa com deficiência e os seus direitos. Sendo assim, as representações sociais sobre a sexualidade das pessoas com deficiência reportaram a duas perspectivas: subjetiva e social.
\end{abstract}

Palavras-chave: representação social, sexualidade, pessoas com deficiência, deficiência física.

\section{Social Representations of University Students with Physical Disability}

\author{
about the Sexuality of Disabled Persons
}

\begin{abstract}
The main objective of this study was to identify and analyze the social representations of university students with physical disability, about the sexuality of disabled persons. Ten physically disabled students, of both sexes, aged 18 years or older, volunteered to participate and were submitted to a semi-structured interview script, associated with a sociodemographic questionnaire. The analysis was developed through software Interface de R pour les Analyses Multidimensionnelles de Textes et de Questionnaire (IRAMUTEQ) by means of a


Descending Hierarchical Classification (DHC) and descriptive statistics using the Statistical Package for the Social Sciences (SPSS). The dendrogram presented as results the concept and experience of sexuality, the family participation, the importance given to the body, the construction of identity as a disabled person and their rights. Thus, the social representations about the sexuality of disabled persons reported to two perspectives: subjective and social.

Keywords: social representation, sexuality, disabled people, physical disability.

\section{Representaciones Sociales de Universitarios con Discapacidad Física sobre}

\section{la Sexualidad de las Personas con Discapacidad}

\section{RESUMEN}

El principal objetivo de este estudio fue identificar y analizar las representaciones sociales de universitarios con discapacidad física, sobre la sexualidad de las personas con discapacidad. Participaron voluntariamente 10 académicos con discapacidad física, de ambos sexos, con edad igual o superior a 18 años, que fueron sometidos a un guión de entrevista semiestructurado, asociado a un cuestionario sociodemográfico. El análisis se desarrolló a través del software Interface de $R$ pour les Analyses Multidimensionnelles de Textes et de Questionnaire (IRAMUTEQ) por medio de una Clasificación Jerárquica Descendente (CJD) y de la estadística descriptiva con el uso del paquete estadístico Statistical Package for the Social Sciences (SPSS). El dendrograma presentó como resultados el concepto y la vivencia de la sexualidad, la participación familiar, la importancia dada al cuerpo, la construcción de la identidad como persona con discapacidad y sus derechos. Siendo así, las representaciones sociales sobre la sexualidad de las personas con discapacidad reportaron a dos perspectivas: subjetiva y social.

Palabras clave: representación social, sexualidad, personas con discapacidad, discapacidad.

A deficiência está presente em 23,9\% da população brasileira, o que representa 45606 048 milhões de pessoas que declararam possuir, ao menos, um tipo de deficiência e o Nordeste é a região onde estão situados os municípios que apresentam maior concentração dessa população (Instituto Brasileiro de Geografia e Estatística [IBGE], 2010). De acordo com Diniz (2007), a deficiência é uma das tantas e diferentes formas de existir no mundo. Tal pensamento remete ao seguinte fato: se, de um lado, estão pessoas que se diferenciam, de outro, encontram-se as pessoas que se igualam. Mas, como saber quem são os diferentes e os iguais?

Para que haja a diferença, é necessário que o contexto social a evidencie e que coloque, em oposição, diferentes e semelhantes, sendo, estes últimos, os possuidores de 
características valorizadas. Essas características correspondem aos padrões ditados pela classe dominante, mas esses padrões são relativos, porque dependem do contexto social, cultural e do período histórico; sendo assim, a diferença, e consequentemente a deficiência, também estão atreladas ao contexto sócio, histórico e cultural (Maia, 2011). Atualmente, segundo o modelo social, a deficiência se caracteriza a partir da interação entre um indivíduo com algum tipo de lesão e/ou limitação e uma sociedade que não está preparada para essa diferença, sem igualdade de condições, que reconheça e respeite a diversidade, garantindo equidade a todos (Diniz, 2007).

Nesse campo das deficiências, a deficiência física corresponde a $7 \%$ do total apresentado anteriormente (IBGE, 2010); ela está relacionada à lesão e/ou limitação na área motora do desenvolvimento humano, podendo possuir etiologia adquirida ou congênita e prognóstico progressivo ou estacionado (Maia, 2006). A expressiva representatividade popular das pessoas com deficiência, em especial, com deficiência física, somada à importância de proporcionar o aumento da participação social e da equidade de condições a essas pessoas, abre espaço para pesquisas sobre diferentes aspectos do seu desenvolvimento e contextos de vida, como, por exemplo, sobre a sua sexualidade.

A sexualidade humana sofreu e sofre influência do recorte temporal, contexto social em que está inserida e das relações culturais, ou seja, ela não é só uma questão biológica, envolve atos, significados e relacionamentos (Bozon, 2004). Sobre a sexualidade das pessoas com deficiência, os estudos nacionais destacam pesquisas referentes a relatos pessoais da vivência sexual, seja sobre relacionamentos amorosos (Luiz \& Kubo, 2007), construção da identidade sexual (Dantas, Silva, \& Carvalho, 2014; Silva \& Albertini, 2007), vulnerabilidade associada a gênero e à deficiência (Nicolau, Schraiber, \& Ayres, 2013), Infecções Sexualmente Transmissíveis (IST) (Aragão, França, Coura, Medeiros, \& Enders, 2016), além de artigos sobre as percepções de outros sujeitos acerca dessa sexualidade: mães (Littig, Cárdia, Reis, \& Ferrão, 2012) e outros responsáveis (algumas mães, um avô e um pai) (Bastos \& Deslandes, 2012).

Dessas pesquisas supracitadas, apenas três envolveram participantes com deficiência física (Aragão et al., 2016; Nicolau et al., 2013; Silva \& Albertini, 2007), sendo que somente a primeira e a última foram desenvolvidas exclusivamente com esse público e apenas o primeiro artigo refere-se a uma pesquisa desenvolvida na região nordeste. Com isso, fica evidente a necessidade de mais pesquisas na temática tanto em território nacional, quanto na região nordestina, onde se encontra a maior representação dessa população, bem como, referente à especificidade da deficiência física. 
A sexualidade das pessoas com deficiência também sofre influência dos padrões sociais, sendo vista socialmente a partir de mitos, tabus e crenças (Maia, 2011), baseados tanto no senso comum quanto no conhecimento científico, sobre a deficiência, suas características e intervenções necessárias; além disso, essas ideias caracterizam preconceitos, estereótipos e/ou crenças errôneos. Buscando compreender esses discursos sociais, Moscovici apresenta o conceito de representação social e a Teoria das Representações Sociais (TRS). Segundo Silva (2009), as representações sociais são formadas individual e coletivamente, servindo como uma forma de interpretação e orientação sobre o mundo. Não se trata de indivíduos e/ou grupos que seguem uma ideologia de forma passiva, mas implica na visão de indivíduo como pensador ativo e autônomo, que constrói e reconstrói representações, a partir de reflexões sobre a realidade que é compartilhada com o grupo.

Alguns pesquisadores já estudaram a sexualidade das pessoas com deficiência a partir da TRS, na perspectiva de pais e educadores (Giami, 2004), de profissionais que prestam serviços a pessoas com deficiência intelectual (Starke, Rosqvist, \& Kuosmanen, 2016) e de adolescentes (Aldana, 2012), por exemplo. Nesses estudos, a pessoa com deficiência foi representada pelos profissionais como problemática, infantil, incapaz e vulnerável. A sexualidade desses sujeitos foi vista pelos educadores como selvagem, desprovida de afetividade e até mesmo de prazer, enquanto que os pais relacionaram-na à pureza, assexualidade e inocência. Por outro lado, os adolescentes mostraram conhecimentos sobre amor, afeto e prazer sexual, desconstruindo as representações apresentadas pelos outros grupos. Destaca-se que esses estudos citados acima, não foram desenvolvidos no contexto brasileiro ou com pessoas com deficiência física.

É importante salientar que a sexualidade é um direito, visto que ela faz parte dos direitos sexuais e reprodutivos. Os direitos sexuais se referem à livre vivência e expressão da sexualidade, seja quanto à orientação sexual, à escolha do parceiro, ao desejo ou não em ter relação sexual, independente da reprodução ou quanto ao direito à educação sexual, sexo seguro e serviços de saúde. Destaca-se a necessidade do respeito a si e ao parceiro, sem violência, discriminações e imposições, medo, vergonha, culpa ou falsas crenças, independente de estado civil, idade ou condição física. Já os direitos reprodutivos estão relacionados à responsabilidade e livre decisão quanto à reprodução, envolvendo quando e quantos filhos se deseja ter, sem discriminação, imposição e violência, além da necessidade de acesso a informações, meios, métodos e técnicas contraceptivas (Ministério da Saúde, 2009). 
Sendo um direito, a sexualidade deve ser garantida e exercida de forma positiva e saudável por todos os indivíduos, inclusive pelas pessoas com deficiência, visto que possuem os mesmos direitos fundamentais de todas as outras pessoas, que devem ser respeitados, visando garantir uma vida tão plena quanto possível (Organização das Nações Unidas [ONU], 1975). Alguns estudos já foram desenvolvidos abordando os direitos sexuais e reprodutivos das pessoas com deficiência, envolvendo temáticas como o exercício desses direitos (Pérez, 2015) e o acesso a serviços de saúde sexual e reprodutiva (Gartrell, Baesel, \& Becker, 2017; Gibson \& Mykitiuk, 2012; Tanabe, Nagujjah, Rimal, Bukania, \& Krause, 2015). Apenas o artigo sobre exercício dos direitos envolve exclusivamente pessoas com deficiência física e, mais uma vez, essa pesquisa não foi desenvolvida em território nacional. Este estudo, desenvolvido no estado de Sergipe, busca responder ao seguinte questionamento: o que as pessoas com deficiência física têm a dizer sobre a sua sexualidade e consequentemente, seus direitos sexuais e reprodutivos? Visando responder a esse questionamento, esta pesquisa objetivou identificar e analisar as representações sociais de universitários com deficiência física sobre a sexualidade das pessoas com deficiência.

\section{Método}

\section{Participantes}

Este estudo qualitativo, com delineamento descritivo, foi desenvolvido a partir de pesquisa de campo. A amostra foi composta voluntariamente por 10 universitários com deficiência física, de cursos das ciências humanas e sociais, de uma instituição pública, distribuídos igualmente entre os sexos masculino e feminino, com idade igual ou superior a 18 anos. O processo de amostragem foi não probabilístico (por conveniência), com uso da técnica snowball, ou seja, não envolve cálculo probabilístico, mas sim, uma seleção de participantes de acordo com o acesso a este público, a partir da técnica snowball, estes participantes selecionados indicam potenciais participantes. A escolha do público levou em consideração a importância de conhecer como esses estudantes, profissionais em formação, compreendem e representam a temática estudada. 


\section{Instrumentos e Procedimentos}

Como instrumentos, foram utilizados o questionário sociodemográfico, para caracterização dos participantes, e a entrevista semiestruturada, com foco nas representações sociais sobre a sexualidade das pessoas com deficiência.

Os primeiros participantes foram indicados por estudantes da instituição e convidados, a partir de contato telefônico, acordando dias e horários para as aplicações que foram conduzidas pela primeira autora, de forma individual, em um espaço institucional. Inicialmente, foi apresentado o Termo de Consentimento Livre e Esclarecido (TCLE) autorizando a gravação de áudio, que teve duração média de 39 minutos (a mínima com 19 minutos e a máxima com 1 hora e 2 minutos). Por fim, foram solicitadas indicações de potenciais participantes.

A pesquisa está baseada na Resolução no 510/2016, do Conselho Nacional de Saúde, e foi submetida ao Comitê de Ética em Pesquisa, envolvendo Seres Humanos da Universidade Federal de Sergipe (CEP-UFS), com o Certificado de Apresentação para Apreciação Ética (CAAE) 81030617.9.0000.5546 e número de parecer de aprovação 2.514.67.

\section{Análise de Dados}

Os dados textuais, produzidos a partir da transcrição das entrevistas, formaram um corpus que foi analisado, utilizando o software IRAMUTEQ (Interface de $\mathrm{R}$ pour les Analyses Multidimensionnelles de Textes et de Questionnaire) versão 0.7, um programa informático gratuito, que permite diferentes tipos de análise de dados textuais, como por exemplo, o cálculo de frequência de palavras, análise de similitude, classificação hierárquica descendente, entre outros (Camargo \& Justo, 2013). O questionário sociodemográfico foi analisado, a partir da estatística descritiva com uso do pacote estatístico SPSS (Statistical Package for the Social Sciences), versão 22.

\section{Resultados e Discussão}

$\mathrm{Na}$ Tabela 1, estão expostos os dados produzidos, a partir do questionário sociodemográfico, construindo uma caracterização dos participantes. Foram utilizados nomes fictícios para garantia do anonimato. 
Tabela 1

Características Sociodemográficas dos Participantes

\begin{tabular}{lllllll}
\hline $\begin{array}{l}\text { Nome } \\
\text { fictício }\end{array}$ & Sexo & Idade & $\begin{array}{l}\text { Etiologia da } \\
\text { deficiência }\end{array}$ & $\begin{array}{l}\text { Relacionamento/ } \\
\text { Estado civil }\end{array}$ & Trabalha & Renda \\
\hline Alice & F & 38 & Adquirida & Casada & Não & 1 salário \\
\hline Arthur & M & 23 & Congênita & Solteiro & Sim & 1 salário \\
\hline Beatriz & F & 42 & Adquirida & Casada & Sim & 3 salários \\
\hline Eduarda & F & 24 & Adquirida & Noiva & Não & 1 salário \\
\hline Gabriel & M & 26 & Congênita & Namorando & Sim & 1 salário \\
\hline Guilherme & M & 52 & Adquirida & Solteiro & Aposentado & 2 salários \\
\hline Laura & F & 27 & Adquirida & Solteira & Não & 1 salário \\
\hline Miguel & M & 59 & Adquirida & Casado & Aposentado & 3 salários \\
\hline Rafael & M & 21 & Congênita & Solteiro & Não & 1 salário \\
\hline Sofia & F & 30 & Congênita & Namorando & Não & 1 salário \\
\hline
\end{tabular}

Nota. F (Feminino); M (Masculino).

A partir dos perfis identificados, $40 \%$ dos participantes possuem deficiência congênita e 60\% adquirida, com média de idade de 34,2 anos (DP =13,113). Entre as mulheres, a média foi de 32,2 anos, duas delas (Beatriz e Eduarda) possuem filhos e, no que se refere à renda, apenas uma trabalha e recebe mais de um salário mínimo, as outras quatro não trabalham e recebem Benefício de Prestação Continuada (BPC), que corresponde a um salário. Quanto aos homens, a média de idade foi de 36,2 anos; um deles (Guilherme) possui filhos e, a respeito da renda, apenas um recebe o BPC, dois trabalham e recebem um salário mínimo e dois já trabalharam e atualmente estão aposentados recebendo mais de um salário.

Os dados produzidos nas entrevistas foram reunidos no corpus "Representações sociais: sexualidade e deficiência" e submetidos a uma Classificação Hierárquica Descendente (CHD), um método de análise que permite classificar os segmentos de texto (ST) de acordo com seus vocabulários, reunindo os que se assemelham e repartindo os que se diferem (Camargo \& Justo, 2013). Foram identificados 10 textos e 1085 ST, compostos por 3200 palavras, com 37146 ocorrências, dando uma média de 11,60 vezes por palavra. A CHD analisou 980 ST $(90,32 \%)$.

O corpus foi dividido em quatro classes. Primeiramente, surgiram dois subcorpus, originando a classe 1 em oposição às outras classes (2, 3 e 4); posteriormente, a classe 4 foi separada e, por fim, as classes 2 e 3 sofreram uma partição, conforme apresentado na Figura 1, que também traz as demais informações sobre as classes, como o nome, quantidade e 
porcentagem de segmentos de texto, além das palavras com maior associação $\left(\mathrm{x}^{2}\right)$ e sua frequência (F). Os resultados e discussões referentes a cada classe serão expostos a seguir, de acordo com a ordem de partição.

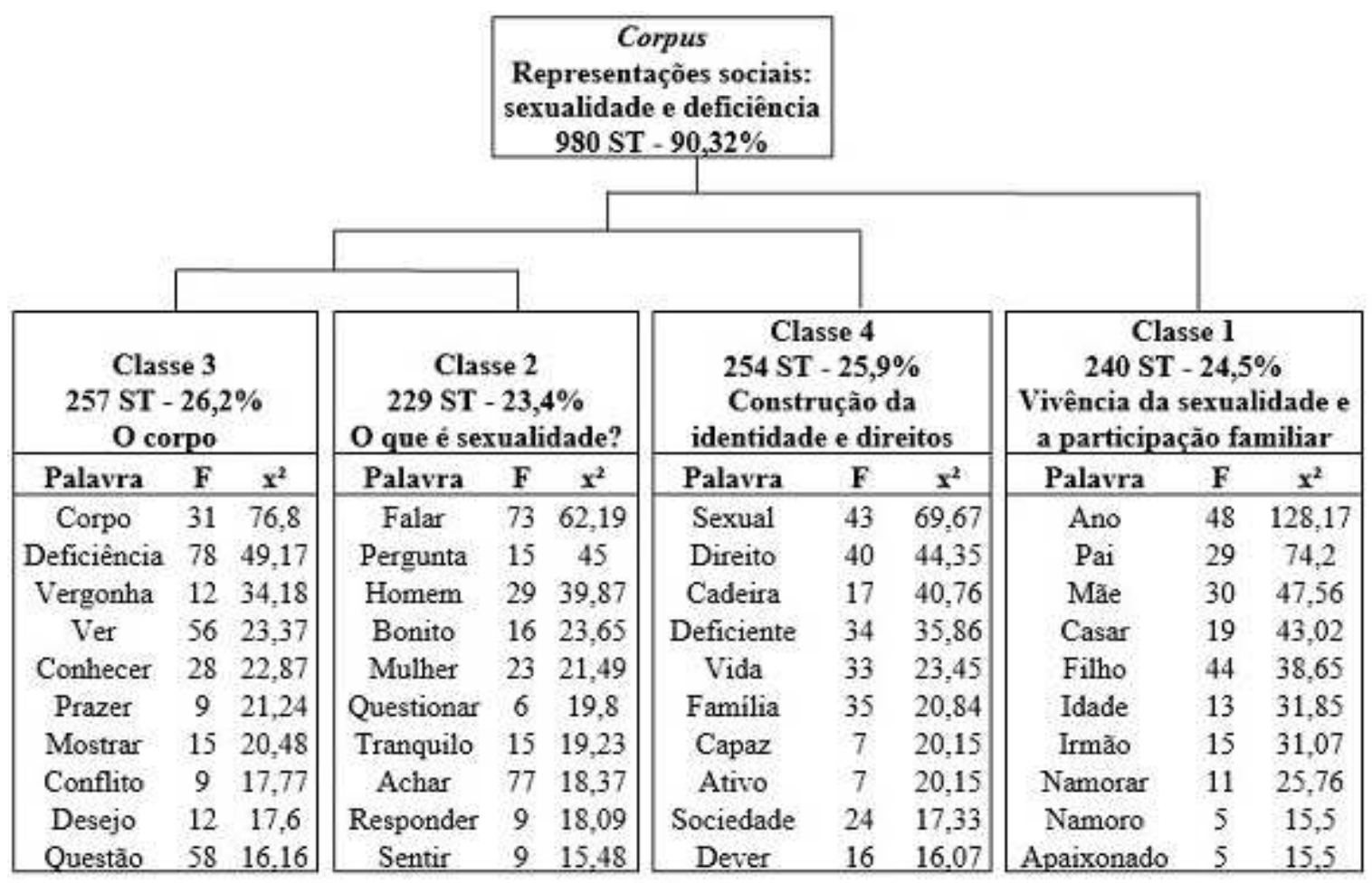

Figura 1. Dendrograma da Classificação Hierárquica Descendente (CHD) do corpus "Representações sociais: sexualidade e deficiência".

\section{Classe 1 - "Vivência da sexualidade e a participação familiar"}

A Classe 1, denominada "Vivência da sexualidade e a participação familiar", é composta por $240 \mathrm{ST}$, que correspondem a $24,5 \%$ do total analisado; nela, estão reunidos conteúdos sobre como a sexualidade foi experienciada, no decorrer da vida, e como se deu a participação da família nesse processo. As expressões "ano" e "idade" aparecem como uma demarcação temporal dos diferentes momentos e histórias, enquanto que a sexualidade é representada em termos como "casar", "namorar", "namoro" e "apaixonado". A fala de Gabriel ilustra bem essa questão:

“... eu tive uma, duas, três namoradas desde os 14 anos de idade. Eu tive uma namoradinha no colégio e enfim, aí, cada relacionamento trouxe uma vivência própria, né? Então, eu sempre fui muito apaixonado por tudo, pela vida, entendeu? 
Eu sempre fui muito vivo, apesar da própria deficiência, eu sempre fui maior que isso...”.

No extrato, percebe-se que a sexualidade é apresentada como algo independente à deficiência, ou seja, inerente ao ser humano, sem distinção e que, assim sendo, as pessoas com deficiência tanto possuem quanto podem vivenciá-la em todos os seus aspectos, assim como todas as outras pessoas, corroborando com os estudos de Chappell (2014) e Luiz e Kubo (2007), por exemplo, que, ao pesquisarem percepções, atitudes e discursos de pessoas com deficiência sobre a sexualidade, constataram semelhanças à sexualidade das pessoas sem deficiência.

A participante Alice deixa claro tal semelhança, quando expõe sobre seu relacionamento e sua intenção de maternidade: "Eu sou casada, casei com 23 anos... tenho 38 e nunca evitei e não tenho filhos, ele (o marido) já tem do primeiro (casamento), quatro (filhos), mas o meu sonho é ter pelo menos um filho ou uma filha." Segundo Bloom, Mosher, Alhusen, Lantos e Hughes (2017), em sua pesquisa sobre desejo e intenção de fertilidade em mulheres com e sem deficiência, ambos os tipos de participantes demonstraram interesse semelhante em ter filhos, confirmando o que foi apresentado anteriormente sobre as semelhanças entre pessoas com e sem deficiência quanto à sexualidade e que, desta forma, a diferença estaria relacionada a outros fatores, como gênero, cultura e família.

No que se refere à família, as palavras "pai”, "mãe", "filho" e "irmão", que também aparecem nessa primeira classe, remetem a participação familiar na construção e vivência da sexualidade, como é possível perceber no trecho a seguir: “...eu venho de uma família que é bem... Meus pais, eles não falam muito sobre isso sabe? E tipo... É uma coisa que eu não comento muito assim, nem com minhas irmãs...” (Laura).

$\mathrm{Na}$ fala, aparece claramente a falta de diálogo familiar acerca da sexualidade, dado comum nos estudos encontrados sobre a temática, nos quais essa atitude é apresentada como uma postura protetiva (McKenzie, 2013) e infantilizadora, negando a sexualidade desses sujeitos, a partir da restrição de informações (Bastos \& Deslandes, 2012; Littig et al., 2012).

Segundo Damas, Pérez, Reyes e López (2015), a superproteção familiar é uma das condições sociais que impedem o desenvolvimento saudável e gratificante da sexualidade na vida das pessoas com deficiência, assim como os preconceitos e estereótipos sociais, que também aparecem no segmento de texto: 
“... a dificuldade de, eu, pra mim encontrar uma namorada, não era a dificuldade, era permanecer com esse namoro entendeu? Por causa disso, porque a família quando vinha, vinha muito... Mas vinha com força, tinha delas que não tinham o que fazer e iam até atrás da minha mãe e atrás do meu pai, no trabalho, pra dizer que não queria esse namoro e tal e pressionava e a guria cedia porque era a família que não queria e acabou história e assim foi garota, isso foi a vida inteira, até quando eu casei e olhe que eu casei com 35 anos...” (Miguel).

O relato de Miguel apresenta um exemplo de discriminação com relação à deficiência e à implicação disso na vivência afetivossexual do participante, trata-se de uma forma de legitimação do corpo com deficiência (Jones, Duarte, Astorga, Pardo, \& Sepúlveda, 2015), baseada em crenças, mitos, tabus e padrões sociais (Maia, 2011), estigmatizando-o e associando-lhe estereótipos, impedindo o desenvolvimento sexual saudável e gratificante (Damas, Pérez, Reyes \& López, 2015). A discriminação também aparece em outros tipos de estudos sobre sexualidade das pessoas com deficiência, associada ao corpo (Agmon, Sa'ar, \& Araten-Bergman, 2016), por exemplo.

Nessa primeira classe, percebe-se que as representações sociais dos universitários com deficiência física sobre a sexualidade das pessoas com deficiência exploraram a vivência dessa sexualidade, tanto de um ponto de vista individual/subjetivo, quanto coletivo/social. $\mathrm{Na}$ perspectiva subjetiva, a sexualidade foi representada, a partir das experiências em diferentes momentos e histórias, como algo independente da deficiência e que está presente em todos, de forma semelhante. Já na concepção social, a vivência da sexualidade foi relacionada à participação da família, a qual foi representada pelos participantes, a partir da falta de diálogo familiar, além dos estereótipos e preconceitos sociais, característicos de discriminação quanto à deficiência e à expressão afetivossexual.

\section{Classe 4 - "Construção da identidade e direitos"}

A sexualidade também foi representada, a partir da ideia de "Construção da identidade e direitos", temática da classe 4, que apresenta 254 ST (25,9\%), na qual, mais uma vez, as representações sociais aparecem em uma perspectiva dualista: individual e coletiva. Os conteúdos sobre a construção identitária como pessoa com deficiência estão associados a termos como "cadeira", "deficiente" e "capaz", alguns presentes no extrato a seguir: 
“... existe várias deficiências, só que quando chega uma pessoa que usa uma cadeira de rodas parece assim: ah é cadeira, é tudo igual! E não é! Não necessariamente é assim. Cada caso é um caso e cada deficiente ele tem um grau de lesão...” (Rafael).

O participante Rafael destaca a forma como a sociedade generaliza os diferentes tipos de deficiência, igualando a todos, baseando-se apenas no uso de um recurso auxiliar comum, como a cadeira de rodas, mas, além disso, ele aproveita para destacar a existência das várias deficiências e das subjetividades associadas a cada caso, relacionando concomitantemente as perspectivas coletiva e individual das representações sociais, isso porque, para as pessoas com deficiência, o coletivo as vê como iguais, generalizando-as e, do ponto de vista individual, a construção da identidade refere-se às diferenças individuais. Cuthbert (2017) alcançou resultados semelhantes em sua pesquisa: os relatos mostraram que a deficiência era vista socialmente como algo que definia a totalidade do sujeito; essas pessoas não eram vistas de acordo com suas características subjetivas, mas por um viés da deficiência, que os tornava iguais, inclusive quanto à sexualidade.

Segundo Dantas et al. (2014), o processo de construção da identidade, como pessoa com deficiência, está associado ao empoderamento e à autoadvocacia perpassados em diferentes contextos de vida desses sujeitos, como a família, a educação, o trabalho e as relações sociais, sendo o empoderamento correspondente à aquisição de consciência, controle e iniciativa diante dos diferentes contextos de vida e a autoadvocacia relacionada à capacidade do sujeito em ser advogado de si mesmo, tendo direito e dever de decidir sobre si. Associados, esses conceitos constroem a ideia de protagonismo.

Uma das formas de empoderamento e autoadvocacia é a reivindicação de direitos, temática que também é destacada nessa classe, representada pelas palavras "direito" ("vida", “sexual”, “ativa” e "família”), “dever" e "sociedade”, como podemos ver, a seguir: “...todo ser humano tem direito a viver, ter uma vida sexualmente ativa, seja o deficiente físico ou não, todos têm os mesmos direitos, se tratam de seres humanos... qualquer pessoa pode ter direito a construir uma família, ter filhos...” (Sofia).

O artigo de McKenzie (2013), já citado anteriormente, apresenta relato de uma postura ativista das pessoas com deficiência, reivindicando o conhecimento social e a necessidade de direitos sobre sua sexualidade, semelhante ao que aparece na fala de Eduarda:

“...eu acredito que a mudança ela vai através do conhecimento, do aprendizado... nós temos relações sim, nós temos filhos, temos família e nós queremos um comparativo 
de igualdade sabe, sem essa questão de inferioridade, sem essa questão de sermos menos, não podermos, não sermos capazes. Eu acredito que o que a pessoa com deficiência quer é que as pessoas entendam que nós temos limitações, mas não somos incapazes de nada, cada um com a sua deficiência, a minha é física, tem auditiva, tem mental, cada um com sua deficiência, ela tem limitações, mas isso não as impedem de nada, inclusive de ter relações sexuais, de ser feliz conforme a escolha dela..."

Nos extratos acima, vemos a representação sobre a sexualidade das pessoas com deficiência, a partir da ideia de direitos, dos pontos de vista: individual, como algo que pertence a todo ser humano, e coletivo, necessitando de uma igualdade, a partir do dever social em conhecer, aceitar e abrir espaço ao exercício sexual e reprodutivo, ou seja, fazer valer os direitos sexuais e reprodutivos desses sujeitos.

Como já destacado introdutoriamente, o desconhecimento social sobre os direitos sexuais e reprodutivos das pessoas com deficiência está relacionado aos poucos e indiretos estudos a seu respeito e implica no descumprimento desses direitos, a partir de diferentes situações, como, por exemplo: a inadequação dos serviços de saúde sexual e reprodutiva, principalmente quanto à acessibilidade, ao tempo de espera, ao transporte, ao aconselhamento, às práticas discriminatórias e à precariedade de informações sobre educação sexual e deficiência (Gibson \& Mykitiuk, 2012); à associação entre deficiência e assexualidade, à inferioridade, à dependência e incompatibilidade à maternidade (Pérez, 2015); à falta de recursos sociais e financeiros (Gartrell et al., 2017); aos riscos de violência conjugal, à limitação da autonomia e à menor consciência sobre os conceitos de saúde sexual e reprodutiva (Tanabe et al., 2015). Percebe-se que se fala bastante sobre privação e violação destes direitos, no entendo, também é importante falar sobre as experiências, vivências e exercício dos direitos sexuais e reprodutivos pelas pessoas com deficiência, visando maior conhecimento social.

\section{Classe 2 - "O que é sexualidade?"}

A classe 2, "O que é sexualidade?" possui a menor quantidade de ST, 229 (23,4\%) e reúne as representações sociais dos participantes sobre conhecimento da sexualidade. Destacam-se os termos "pergunta", "questionar", "responder", "achar" e "tranquilo" que se relacionam à palavra com maior associação à classe o verbo "falar", ou seja, o falar sobre sexualidade, como é possível identificar no extrato: 
“...eu falo numa boa sobre essa questão da sexualidade... falar na possibilidade de ser pai ou não, ou qualquer outra coisa envolvendo a sexualidade... eu posso falar com qualquer pessoa, se a pessoa se sentir à vontade... eu não vou sair te contando... se eu for questionado, eu sou bem franco para responder... com meus amigos, eu costumo falar sobre sexualidade, seja na resenha, seja algo sério, algo que possa ter acontecido e seja um desabafo, mas sempre foi algo tranquilo... A gente sabe que a nossa sociedade é um pouco retrógrada mesmo, preconceituosa, talvez você encontre outros participantes que já tiveram algum problema, ou algum empecilho em relação a isso, ou que não se sinta à vontade pra falar sobre isso, mas eu sou muito tranquilo, nunca me falaram nada, nunca vieram com perguntas do tipo... Pra saber... 'Ah, como é que você faz? O que é que você sente? Qual é o jeito que você faz?' Sexualidade é uma coisa que tá pra todo mundo, quem se limita são as pessoas, deficiência é só uma dificuldade!” (Arthur).

A fala de Arthur reforça as conclusões encontradas na classe 1, pois, assim como há semelhança entre a vivência sexual das pessoas com deficiência às das demais pessoas, os diálogos sobre esse assunto também não se diferenciam. Aqui, a sexualidade é representada a partir das conversas, sendo que, individualmente, esses diálogos são descritos como comuns e tranquilos, pois a sexualidade está presente em todos, e coletivamente, o participante vê a sociedade como retrógrada e preconceituosa para compreender ou por questionar a sexualidade das pessoas com deficiência.

A sexualidade é uma característica de todos os indivíduos; ela tanto está presente, como se manifesta a partir da nossa genitalidade, das nossas emoções e sentimentos, além de ser uma questão cultural, social e histórica (Maia, 2011). As representações sociais sobre a sexualidade, assim como qualquer outro tipo de representação, são construídas e compartilhadas individual e socialmente, dando explicações e fundamentando as atitudes sociais sobre as coisas, fenômenos e pessoas. Ainda nessa classe, os substantivos "homem" e "mulher" e o verbo "sentir" se destacam entre os segmentos de texto:

“...tem a sexualidade que você nasce com ela, que te diz que você é homem ou você é mulher, essa coisa binária que a gente fala e tem a sexualidade levando pro lado da... O que você sente pelo outro, que pode ser o seu oposto ou não... Ela representa o que 
eu sou, o que eu sinto, a minha, sei lá, minha necessidade, o meu jeito, a minha sexualidade é aquilo que eu sou” (Arthur).

Nesse extrato, a sexualidade é representada a partir da associação aos conceitos de gênero, orientação sexual e identidade. Porém, muitas vezes, ela é relacionada exclusivamente a um desses aspectos, como estudado por Silva e Albertini (2007), que apresentaram, em sua pesquisa, a sexualidade, a partir de uma concepção de gênero. Outro exemplo é a pesquisa de Luiz e Kubo (2007) que deram maior evidência às emoções e sentimentos e que também estudaram os aspectos físicos e os comportamentos como atributos considerados atrativos. Essa última temática também aparece nessa classe, a partir do uso do adjetivo "bonito" relacionado as representações sobre sexualidade ao que é considerado atrativo em si e no outro, como é possível perceber no extrato da entrevista com Guilherme: “...modo de falar, souber falar também né? Que às vezes é bonita, eu falo com a pessoa, só sai besteira, também não adianta, eu acho que é isso né? Tem que ter beleza física...”.

Guilherme representa a sexualidade, a partir de atributos, como a beleza física e o modo de falar, diferente dos resultados encontrados por Chappell (2014), nos quais os aspectos físicos, caracterizados pela presença ou não de deficiência, não foram considerados como critérios ao relacionamento, mas sim à personalidade.

As representações apresentadas nessa classe, sobre sexualidade, reportaram ao falar sobre a temática, seja de um ponto de vista subjetivo, sobre experiências e opiniões, ou de um ponto coletivo, sobre o julgamento e questionamento social relacionado a essas experiências e discursos. Além disso, a sexualidade também foi representada por aspectos que a compõe (gênero, orientação sexual e atributos físicos), comportamentos e como parte da identidade do sujeito, conceitos que mais uma vez confiram duas perspectivas (subjetiva e social) de representação, pois, tratam-se de ideologias construídas socialmente, mas que são reconstruídas pelo sujeito para orientá-lo em sua interpretação sobre o assunto.

\section{Classe 3 - "O corpo"}

Levados em consideração ou não, na hora da escolha do parceiro, comportamentos e aspectos físicos aparecem nos resultados e, mais especificamente, "O corpo" é destaque na classe 3, que possui a maior parte dos ST, 257 ao todo, o que representa uma parcela de $26,2 \%$ do total, na qual são abordadas as representações sociais sobre a sexualidade, a partir de sentimentos (“desejo", “conflito", "prazer" e "vergonha”) e comportamentos (“conhecer", 
"ver" e "mostrar") relacionados ao "corpo" com "deficiência" e sua repercussão na vivência sexual. Inicialmente, a deficiência é citada como uma "questão", uma característica de diferença, como se apresenta no trecho:

“...comecei a perceber o olhar de estranhamento, aí eu vi né? Tem algo diferente em mim. Ai vem a questão das rejeições, quando parte até pela questão mesmo da adolescência que, é aquela parte que, eu diria um pouco gritante, porque é a hora que você começa a olha mais o seu corpo, você começa a sentir desejos e ver que o outro já não te olha, quando olha até você percebe que gostou, mas quando notou que você tem um deficiência já muda. Ai vem a parte do complexo nesse momento, eu me via realmente como uma pessoa deficiente, incapaz de conseguir arrumar alguém... eu não me sentia uma pessoa que pudesse despertar a sexualidade do outro, pelo fato da questão da deficiência...” (Beatriz).

$\mathrm{Na}$ fala da participante percebe-se o corpo com deficiência visto de uma perspectiva de diferença, como abordado no estudo de Agmon et al. (2016), no qual esse corpo foi apresentado como incapaz, dependente, assexuado, vulnerável e privado de seus papéis de gênero e que, sendo assim, a construção da autoimagem corporal estaria como um reflexo da constatação de tal diferença pelo sujeito e em seus sentimentos, como a vergonha, as preocupações em relação à própria estética corporal e à atratividade, a questões como a legitimidade de papéis de gênero e as atitudes sociais negativas (Jones B. et al., 2015). No entanto, a seguir, a participante apresenta uma fala sobre a reconstrução de suas representações sociais sobre sexualidade associada ao corpo:

“...hoje não, depois de tudo há uma aceitação né, que é o primeiro passo... vai amadurecendo, você percebe que não, que você tem condições sim, você tem que buscar... eи fui descobrindo o meu próprio corpo. Então, eu passei por essa fase também de procurar me conhecer né? De examinar meu próprio corpo, entender o que acontecia com ele... eu vi que eu poderia é... Ter esse prazer né? A partir de mim, do que passa por dentro de mim, até pelo próprio corpo. Então, hoje é tranquilo, a forma que eu sei que eu posso passar para o outro esse desejo também...”

Beatriz apresenta em sua fala que, diferente do que se encontrou nos resultados dos estudos citados anteriormente (Agmon et al., 2016; Jones et al., 2015), é possível vivenciar a 
sexualidade a partir de um corpo com deficiência, ou seja, o corpo com deficiência é capaz, é sexuado, não é privado de papéis de gênero, por isso e para isso é necessário a aceitação, o amadurecimento, a busca, a descoberta e o autoconhecimento, contribuindo para a construção da autoimagem corporal positiva entre as pessoas com deficiência, a valorização de sua estética corporal, atratividade e consequentemente a desconstrução de atitudes sociais negativas e a construção de novas representações que veem esse corpo como fonte de prazer e desejo.

A perspectiva dualista das representações sociais sobre sexualidade também se faz presente quando associadas ao corpo. Incialmente, quando o corpo é representado pelos sentimentos de vergonha, conflito e como uma questão, trata-se de sentimentos vivenciados pela participante (subjetivo), mas que são causados pelo olhar do outro (social). A seguir, a partir da reconstrução dessas representações, surgem sentimentos de desejo e prazer, em uma esfera subjetiva, de autoconhecimento e descoberta pessoal e no que é passado para o outro, ou seja, o desejo e o prazer despertado.

\section{Considerações Finais}

Nas quatro classes apresentadas e analisadas, é possível perceber as representações sociais dos participantes sobre a sexualidade das pessoas com deficiência em diferentes aspectos: conhecimento e vivência da sexualidade, o corpo e a participação da família nessa vivência, construção da identidade como pessoa com deficiência e direitos. Essas representações partiram principalmente de duas perspectivas: individual e coletiva. Isso porque os participantes apresentaram suas experiências pessoais referentes à sexualidade e como percebem a postura social para com eles nessas situações.

$\mathrm{Na}$ perspectiva individual das representações, as falas dos participantes apresentaram conhecimento, desejos e vivência da sexualidade, ou seja, as pessoas com deficiência conhecem, desejam e vivenciam a sexualidade, necessitando de igualdade de direitos sexuais e reprodutivos, a partir do dever social em conhecer, aceitar e abrir espaços. O corpo com deficiência foi representado inicialmente como uma característica de distinção, repercutindo na construção da imagem corporal, associada a sentimentos como conflito, vergonha e preocupação com a estética, com a atratividade e com o cumprimento dos papéis de gênero, além das atitudes sociais negativas. A partir do autoconhecimento, há uma reconstrução dessa representação para uma visão de corpo com deficiência como fonte de prazer e desejo. No que 
se refere à construção da identidade, os participantes enfatizaram a existência das diferentes e variadas deficiências e da subjetividade presente em cada uma delas.

$\mathrm{Na}$ perspectiva coletiva, a família foi representada a partir da falta de diálogo sobre sexualidade, sendo protetiva, infantilizadora, negando e restringindo informações. E a sociedade foi apresentada como generalizadora dos diferentes tipos de deficiência, sendo a deficiência e a expressão sexual focos de discriminação social por preconceitos e estereótipos. Considera-se, como limitações, o fato do estudo ter sido desenvolvido exclusivamente com universitários, em apenas uma instituição, com um tipo de deficiência (física). Tais limitações podem ser superadas, a partir de pesquisas que envolvam diferentes contextos ou mais instituições de ensino, distintos tipos de deficiência, além de variados níveis de escolaridade, possibilitando maior abrangência, ampliando os resultados apresentados e contribuindo com os estudos na temática.

\section{Referências}

Agmon, M., Sa'ar, A., \& Araten-Bergman, T. (2016). The person in the disabled body: A perspective on culture and personhood from the margins. International Journal for Equity in Health, 15(147), 1-11. doi:10.1186/s12939-016-0437-2

Aldana, J. C. (2012). Representaciones sociales sobre la salud sexual y la sexualidad de adolescentes sordos y oyentes en Bogotá, Colombia (Tese de Doutorado). Faculdade de Medicina, Universidad Nacional de Colombia, Bogotá, Colômbia. Recuperado de https://cultura-sorda.org/wp-content/uploads/2015/04/Tesis-Collazos-2012.pdf

Aragão, J. S., França, I. S. X., Coura, A. S., Medeiros, C. C. M., \& Enders, B. C. (2016). Vulnerabilidade associada às infecções sexualmente transmissíveis em pessoas com deficiência física. Ciência \& Saúde Coletiva, 21(10), 3143-3152. doi:10.1590/1413812320152110.20062016

Bastos, O. M., \& Deslandes, S. F. (2012). Sexualidade e deficiência intelectual: Narrativas de pais de adolescentes. Physis: Revista de Saúde Coletiva, 22(3), 1031-1046. doi:10.1590/S0103-73312012000300010

Bloom, T. E., Mosher, W., Alhusen, J., Lantos, H., \& Hughes, R. B. (2017). Fertility desires and intentions among U.S. women by disability status: Findings from the 2011-2013 national survey of family growth. Maternal and Child Health Journal, 21(8), 16061615. doi:10.1007/s10995-016-2250-3 
Bozon, M. (2004). Sociologia da Sexualidade (M. L. Menezes, Trad.). Rio de Janeiro: FGV. (Obra original publicada em 2002)

Camargo, B. V., \& Justo, A. M. (2013). IRAMUTEQ: Um software gratuito para análise de dados textuais. Temas em Psicologia, 21(2), 513-518. doi:10.9788/TP2013.2-16

Chappell, P. (2014). How Zulu-speaking youth with physical and visual disabilities understand love and relationships in constructing their sexual identities. Culture, Health \& Sexuality, 16(9), 1156-1168. doi:10.1080/13691058.2014.933878

Cuthbert, K. (2017). You have to be normal to be abnormal: An empirically grounded exploration of the intersection of asexuality and disability. Sociology, 51(2), 241-257. doi:10.1177/0038038515587639

Damas, M. A., Pérez, Z. C., Reyes, N. M., \& López, A. B. (2015). Sexualidad y discapacidad: Enfrentando estereotipos desde el documental audiovisual. Revista Cubana de Información en Ciencias de la Salud, 26(3), 273-279. Recuperado de http://scielo.sld.cu/scielo.php?script=sci_arttext\&pid=S2307-21132015000300007

Dantas, T. C., Silva, J. S. S., \& Carvalho, M. E. P. (2014). Entrelace entre gênero, sexualidade e deficiência: Uma história feminina de rupturas e empoderamento. Revista Brasileira de Educação Especial, 20(4), 555-568. doi:10.1590/S1413-65382014000400007

Diniz, D. (2007). O que é deficiência. São Paulo, SP: Brasiliense.

Gartrell, A., Baesel, K., \& Becker, C. (2017). "We do not dare to love": Women with disabilities' sexual and reproductive health and rights in rural Cambodia. Reproductive Health Matters, 25(50), 31-42. doi:10.1080/09688080.2017.1332447

Giami, A. (2004). O anjo e a fera: Sexualidade, deficiência mental, instituição. São Paulo, SP: Casa do Psicólogo.

Gibson, B. E., \& Mykitiuk, R. (2012). Health care access and support for disabled women in Canada: Falling short of the UN Convention on the Rights of Persons with Disabilities: A qualitative study. Women's Health Issues, 22(1), 111-118. doi:10.1016/j.whi.2011.07.011

Instituto Brasileiro de Geografia e Estatística. (2010). Censo demográfico: Características gerais da população, religião e pessoas com deficiência. Rio de Janeiro: IBGE. Recuperado de https://biblioteca.ibge.gov.br/visualizacao/periodicos/94/cd_2010_religiao_deficiencia .pdf

Jones B., S., Duarte B., T., Astorga U., N., Pardo, M., \& Sepúlveda, R. (2015). Aproximación a la experiencia de cuerpo y sexualidad de un grupo de mujeres chilenas con 
discapacidad fisica congenita. Revista Chilena de Terapia Ocupacional, 15(1), 19-32. doi:10.5354/0719-5346.2015.37127

Littig, P. M. C. B., Cardia, D. R., Reis, L. B., \& Ferrão, E. S. (2012). Sexualidade na deficiência intelectual: Uma análise das percepções de mães de adolescentes especiais. Revista Brasileira de Educação Especial, 18(3), 469-486. doi:10.1590/S141365382012000300008

Luiz, E. C., \& Kubo, O. M. (2007). Percepções de jovens com Síndrome de Down sobre relacionar-se amorosamente. Revista Brasileira de Educação Especial, 13(2), 219238. doi:10.1590/S1413-65382007000200006

Maia, A. C. B. (2006). Sexualidade e deficiências. São Paulo, SP: UNESP.

Maia, A. C. B. (2011). Inclusão e sexualidade: Na voz de pessoas com deficiência física. Curitiba, PR: Juruá.

McKenzie, J. A. (2013). Disabled people in rural South Africa talk about sexuality. Culture Health \& Sexuality, 15(3), 372-386. doi:10.1080/13691058.2012.748936

Ministério da Saúde. Secretaria de Atenção à Saúde. (2009). Direitos sexuais, direitos reprodutivos e métodos anticoncepcionais. Brasília, DF: o autor. Recuperado de http://bvsms.saude.gov.br/bvs/publicacoes/direitos_sexuais_reprodutivos_metodos_an ticoncepcionais.pdf

Nicolau, S. M., Schraiber, L. B., \& Ayres, J. R. C. M. (2013). Mulheres com deficiencia e sua dupla vulnerabilidade: Contribuições para a construção da integralidade em saúde. Ciência \& Saúde Coletiva, 18(3), 863-872. doi:10.1590/S1413-81232013000300032

Organização das Nações Unidas. (1975). Declaração dos Direitos das pessoas deficientes. Brasília, DF: Portal MEC. Recuperado de http://portal.mec.gov.br/seesp/arquivos/pdf/dec_def.pdf

Pérez, M. P. C. (2015). Acceso a derechos sexuales y reproductivos de las mujeres con discapacidad: El papel de las y los prestadores de servicios. La ventana: Revista de Estudios de Género, 5(42), 7-45. Recuperado de http://www.scielo.org.mx/scielo.php?script=sci_arttext\&pid=S140594362015000200007

Silva, L. C. A., \& Albertini, P. (2007). A reinvenção da sexualidade masculina na paraplegia adquirida. Revista do Departamento de Psicologia UFF, 19(1), 37-48. doi:10.1590/S0104-80232007000100003 
Silva, N. M. A. (2009). Cada Curica em seu nicho: O pertencimento à linha de pesquisa. In N. M. A. Silva (Org.), Representações sociais em educação: Determinantes teóricos e pesquisa (pp. 17-34). Blumenau, SC: Edifurb.

Starke, M., Rosqvist, H. B., \& Kuosmanen, J. (2016). Eternal children? Professionals' constructions of women with an intellectual disability who are victims of sexual crime. Sexuality and Disability, 34(3), 315-328. doi:10.1007/s11195-016-9441-0

Tanabe, M., Nagujjah, Y., Rimal, N., Bukania, F., \& Krause, S. (2015). Intersecting sexual and reproductive health and disability in humanitarian settings: Risks, Needs, and capacities of refugees with disabilities in Kenya, Nepal, and Uganda. Sexuality and Disability, 33(4), 411-427. doi:10.1007/s11195-015-9419-3

\section{Endereço para correspondência}

\section{Alana Nagai Lins de Carvalho}

Rua Pedro Lins Barreto, 47 casa, Centro, Adustina - BA, Brasil. CEP 48435-000

Endereço eletrônico: alana_adustina@hotmail.com

\section{Joilson Pereira da Silva}

Programa de Pós-Graduação em Psicologia (PPGPSI) - Didática II - $1^{\circ}$ andar.

Avenida Marechal Rondon, s/n, Jardim Rosa Elze, São Cristóvão - SE, Brasil. CEP 491000-000

Endereço eletrônico: joilsonp@ hotmail.com

Recebido em: 02/04/2019

Reformulado em: 22/06/2020

Aceito em: 03/07/2020

\section{Notas}

* Mestre em Psicologia pela Universidade Federal de Sergipe.

** Docente do Programa de Pós-graduação em Psicologia da Universidade Federal de Sergipe, São Cristóvão, SE, Brasil.

Financiamento: O presente trabalho foi realizado com apoio da Coordenação de Aperfeiçoamento de Pessoal de Nível Superior - Brasil (CAPES) - Código de Financiamento 001.

Este artigo de revista Estudos e Pesquisas em Psicologia é licenciado sob uma Licença Creative Commons Atribuição-Não Comercial 3.0 Não Adaptada. 